\title{
Enterprise Social Media Research
}

\author{
Bing $\mathrm{Wu}^{1 *}$ and Chenyan Zhang ${ }^{2}$ \\ ${ }^{1}$ School of Economics and Management, Tongji University, Shanghai, China \\ ${ }^{2}$ Logistics Research Center, Shanghai Maritime University, Shanghai, China \\ ${ }^{*}$ Corresponding author
}

\begin{abstract}
There is a rapid growth of interest in understanding Enterprise Social Media (ESM). This article focused on a review of this topic from science citation index expanded (SCIEXPANED) and Social Sciences Citation Index (SSCI) database on web of science. Research results indicated that (1) the number of citations on these topics mainly distributes in recent 3 years, reaching climax of 25 in 2016; (2) the main research territory is USA, accounting for $50 \%$, then followed by Netherland of $20 \%$; (3) the year of published articles distributes between 2014 and 2016; (4) in the view of research area, there are 5 main areas: information science library science, business economics, psychology, communication and computer science. Overall, the related research topics can be classified into four aspects: definition and history, employee behavior, knowledge sharing on ESM, and cross-boundary communication.
\end{abstract}

Keywords-enterprise social media; behavior; knowledge sharing; cross-boundary

\section{INTRODUCTION}

Social media are increasingly implemented in work organizations as tools for communication among employees. Social media technologies in organizational contexts frequently referred to as Enterprise Social Media (ESM). ESM encompass a range of information and communication tools (ICTs) for supporting interaction, collaboration, and co-creation.

The proliferation of ESM can facilitate knowledge sharing. [1] in the organization. It is important that we develop an understanding of how ESM enabled and constrained the communicative activities through which work is accomplished.

A number of organizations are grappling with the challenge of devising a enterprise social media (ESM) strategy. Therefore such thinking has been externally focused and restricted to an analysis of how social-media outlets might be integrated into their marketing and advertising strategies. The focus of enterprise social media is not simply to encourage people to use the platform more, but to use it to accomplish business objectives more efficiently or effectively. However, how to use it to accomplish business objectives more efficiently or effectively is a key issue in ESM.

Over the last several years, some firms have adopted various types of ESM, such as blogs and wikis, for internal use. Increasingly, several leading organizations have ESM to encourage their employees to communicate [2]. Prominent adopters include General Motors, IBM, HP, Microsoft, Infosys, Google, and Charles Schwab, among others. From an internal perspective, some have argued that the organizational adoption of ESM such as enterprise blogs will improve access to knowledge experts, increase the rates of problem solving and new-product development, and reduce the costs of internal communication. The general thinking within such firms is that ESM can provide a structured platform to support employee participation in brainstorming and idea sharing, thus deepening a company's pool of knowledge. Therefore, the use of ESM as a mechanism for knowledge management has increased their adoption in enterprises [3].

In recent years, organizations have widely deployed ESM for internal use. Companies can use ESM internally to initiate conversations between management and employees. If employees feel that they are involved in the conversation, they will be greater loyalty and productivity. ESM is also useful for product development and informing the company of upcoming initiatives. ESM can be more effective, as they eliminate the need to answer a given question multiple times and allow for feedback from the entire group as opposed to just the email recipient.

The rest of this article is organized as follows: Section 2 surveys the relating results analysis of ESM literatures. Section 3 briefly summarizes related work within ESM. Section 4 concludes the article with a summary of our key results and discusses new opportunities for future research.

\section{ANALYSIS RESULTS OF RELATING LITERATURES}

According to Science Citation Index Expanded and Social Sciences Citation Index Database in web of science, 10 articles title as "enterprise social media" excluding the conferences papers are found in related discipline in recent five years.

\section{A. Results of Citation Report}

Published items in each year were shown in FIG I, which illustrated the tendency of increased research from 2013, reaching climax in 2016. Accordingly, citations increased from 2014 and the highest citations happened in 2016, as shown in FIGURE II.
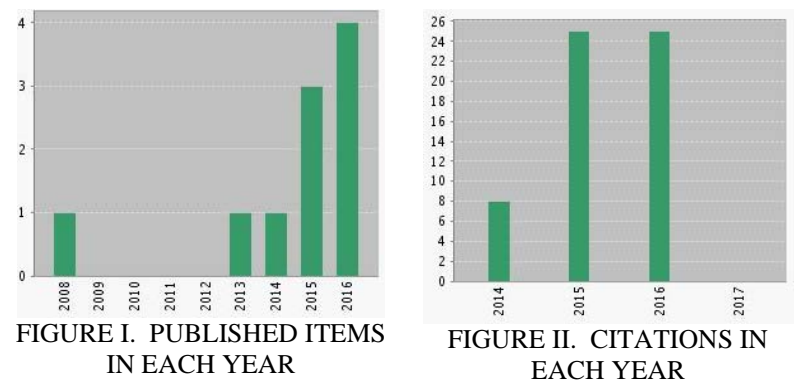


\section{B. Results of Countries/Territories}

According to TABLE I of the analysis of countries/territories, USA and NETHERLANDS ranked in Top 2. Especially, USA accounts for 50\%, and NETHERLAND accounts for $20 \%$.

\section{TABLE I. COUNTRIES/TERRITORIES}

\begin{tabular}{|c|c|c|}
\hline Countries/Territories & Record Count & $\%$ of 10 \\
\hline USA & 5 & $50 \%$ \\
\hline NETHERLANDS & 2 & $20 \%$ \\
\hline
\end{tabular}

\section{Results of Organizations}

In the view of organizations, both MICHIGAN STATE UNIV and VRUE UNIV AMSTERDAM have the same record count of 2, accounting for $20 \%$ respectively in Table II.

TABLE II. ORGANIZATIONS

\begin{tabular}{|c|c|c|}
\hline Organizations & Record Count & $\%$ of 10 \\
\hline MICHIGAN STATE UNIV & 2 & $20 \%$ \\
\hline VRUE UNIV AMSTERDAM & 2 & $20 \%$ \\
\hline
\end{tabular}

\section{Results of Publication Years}

In line with the citations tendency in Figure II, 70\% researches published in 2015 and 2016, as shown in Table III.

TABLE III. PUBLICATION YEARS

\begin{tabular}{|c|c|c|}
\hline Publication Years & Record Count & $\%$ of 10 \\
\hline 2016 & 4 & $40 \%$ \\
\hline 2015 & 3 & $30 \%$ \\
\hline
\end{tabular}

\section{E. Results of Research Areas}

According to Table IV, $60 \%$ of the research focused in information science library science, then $40 \%$ in business economics and $30 \%$ in psychology.

TABLE IV. RESEARCH AREAS

\begin{tabular}{|c|c|c|}
\hline Research Areas & Record Count & $\%$ of 10 \\
\hline $\begin{array}{c}\text { INFORMATION SCIENCE } \\
\text { LIBRARY SCIENCE }\end{array}$ & 6 & $60 \%$ \\
\hline BUSINESS ECONOMICS & 4 & $40 \%$ \\
\hline PSYCHOLOGY & 3 & $30 \%$ \\
\hline COMMUNICATION & 2 & $20 \%$ \\
\hline COMPUTER SCIENCE & 2 & $20 \%$ \\
\hline
\end{tabular}

\section{F. $\quad$ Results of Document Types}

Mostly, the document type is article, accounting for $80 \%$. Whilst, editorial material accounts for $20 \%$, as shown in Table V.

TABLE V. DOCUMENT TYPES

\begin{tabular}{|c|c|c|}
\hline Document Types & Record Count & $\%$ of 10 \\
\hline ARTICLE & 8 & $80 \%$ \\
\hline EDITORIAL MATERIAL & 2 & $20 \%$ \\
\hline
\end{tabular}

\section{G. Results of Source Titles}

As a result of $60 \%$ research areas existing in information science library, 2 records are found in Journal of Computer Mediated Communication and Journal of Information Technology respectively, as shown in TABLE VI.
TABLE VI. SOURCE TITLES

\begin{tabular}{|c|c|c|}
\hline Source Titles & Record Count & \% of 10 \\
\hline $\begin{array}{c}\text { Journal of Computer Mediated } \\
\text { Communication }\end{array}$ & 2 & $20 \%$ \\
\hline Journal of Information Technology & 2 & $20 \%$ \\
\hline
\end{tabular}

\section{RELATING TOPICS OF ESM}

We review areas of research covered by papers in ESM to take the current state of and to propose directions for future research. Generally, relating topics and be identified from 4 aspects: definition and history, employee behavior, knowledge sharing on ESM, and cross-boundary communication.

\section{A. Defition and History}

ESM seem to have been used in two primary ways. The first way, and more commonly studied, is for organizational communication with external parties, such as customers, vendors, and the public at large [4]. Most organizations that use social media to communicate with external parties have a multipronged strategy that crosses various platforms [5]. The second way, less commonly studied way in which organizations have employed social media, is for internal communication and social interaction within the enterprise. And these internal ESM are our focus.

Some articles have provided a framework for considering the design decisions for an ESM platform. The framework provides a productive and simple way to think about the effect of social media on the enterprise that moves beyond a discussion of the merits of specific platforms or currently available features [6]. The combination of rigorous academic research and practical examples provides business and IT managers with a valuable resource as they think about the future possibilities of ESM [7].

\section{B. Employee Behavior}

Employees' motivations to ESM may not always align with a firm's objectives. In ESM, work and leisure related content often coexist on the same page. Thus, some employees' posts may not be relevant to their work related knowledge or professional expertise. Some firms believe that such behavior can undermine the purpose of ESM. Therefore, it is increasingly important to understand employees' behavior in an ESM setting to gain insights into how firms' policy interventions can influence employee behavior [8].

Typically, employees' propensity to create or consume content on an ESM is constrained by the time available for such activities. Thus, the utility they derive from ESM is determined by a trade-off between work and leisure related content. Employees also face another trade-off between how much time to spend on content generation and content consumption.

Users make choices concerning reading and writing based on their preferences for two types of content. A dynamic structural model in which the employees of an enterprise compete in the process of reading and writing posts is presented to indicate how popular employees are among their professional peers, and the more popular they are, the happier they are likely to be at work [9]. 
Evidence of competition among employees with respect to attracting readership for their posts were found to identify a tension that peer blogging activity raises for an employee. As a blogger, an employee would prefer reduced readership competition and, hence, fewer of peers to post. In contrast, as a reader, the same employee would prefer peers to post more, as this increases her rate of learning [10].

As two types of user generated contents coexist on the same platform, this spillover is bidirectional in nature. Although readership for leisure posts provides less direct utility than that of work posts, employees nevertheless post a significant number of leisure posts, because there is a significant spillover effect on the readership of work posts from the creation of leisure posts.

Overall, these results shed light on how enterprise adoption of social-media tools influences employee's behavior and choices in ESM.

\section{Knowledge Sharing on ESM}

By complementing the affordance perspective with an institutional logics perspective, research on the use of ESM for organizational knowledge sharing shows that professionals face ambiguities because their knowledge sharing behavior is informed by an institutional complexity with logics of the profession, and logics of the corporation [11].

Affordances as a priori concepts in the qualitative case study of an ESM at an IT consultancy organization shows that professionals find ways to manage the ambiguities they experience by engaging the affordances of ESM in such a way as to develop coping practices, such as connection management, reputation management, and information management.

To understand how ESM support and facilitate knowledge sharing, scholars have identified several affordances. While the affordance literature has various interpretations such as perceived affordances and technological affordances, a relational perspective on affordances is most commonly used in the literature on information systems (IS) and computermediated communication (CMC).

It emphasizes the entanglement of the intentions and goals of an actor interacting with an IT artifact, and sees this mutual relationship as situated and emergent in practice [12].

To examine the influence of the knowledge sharing activities and individual job performance within ESM, the empirical analysis reveals that knowledge self-efficacy, social interaction ties, and the norm of reciprocity positively influence knowledge sharing activities in ESM [13].

Although enjoyment of helping does not have a significant influence, knowledge-sharing activities in ESM influences individual job performance.

\section{Cross-Boundary Communication}

Today, the proliferation of ESM in organizational contexts has profound implications for the ability of groups in organizational to engage in team boundary-spanning activities [14].
Collaborating across boundaries is important for organizational innovation. New technologies such as ESM are often implemented for their open infrastructure, democratic nature, and ability to break down traditional hierarchies and barriers to communication; thus, such tools may be expected to play a role in facilitating cross-boundary interaction.

Using data from qualitative way and quantitative way, the study addresses two important research questions regarding the empirical relationship between team boundary spanning and ESM to understand the types of team boundary-spanning activities that group members enact through ESM and the effects of ESM on extra-team stakeholders' perceptions and reciprocating actions by the team boundary-spanning activities of these group members [15]. The results of the study show that ESM, largely as a function of visibility affordance, supports a narrow set of representational activities, but offers only limited support for information search and coordination. Furthermore, the findings reveal that ESM activity has a positive effect on extra-team stakeholders' recognition and financial support of the representational ESM posts emanating from the boundaryspanning group.

On the basis of above goals, the central questions relating with cross-boundary communication include: What types of boundary-spanning activities are enacted by group members through ESM? Do different group members, as defined by their hierarchical position in the group, enact distinct types of boundary-spanning activities? What is the role of ESM in the formation of perceptions and reciprocating actions by extrateam stakeholders? Does the hierarchical position of extra-team stakeholders affect the likelihood of reciprocating actions?

Given the lack of empirical research on the use of ESM for team boundary spanning and the one-sided focus of the team boundary spanning literature on internal group members, researches set out to research these questions aimed at understanding the types of intra organizational team boundaryspanning activities that are enacted by groups through ESM and how ESM influences the perceptions and reciprocations of these activities by extra team stakeholders.

Drawing on a mixed-methods case study of a large Russian telecommunications company, the introduction of an ESM application and the degree to which it promotes crossboundary communication across geographical and hierarchical lines was empirically assessed through analysis of server log data and in-depth interviews[16].

Overall, interviewees felt that the introduction of ESM had a profound influence in increasing knowledge sharing and communication across hierarchical and geographical boundaries. It was verified by actual communication patterns in the ESM that showed evidence of increasing cross-boundary communication among regions, but decreasing crosshierarchical communication as usage became more diffused among lower level specialists. And research findings demonstrate that ESM promotes cross-boundary communication, although there are distinct patterns for hierarchical and regional boundaries and usage patterns are likely to be shaped by existing cultural factors within the organizational and national contexts. Moreover, the findings suggest that top managers were active in driving the ESM 
adoption process as part of a larger change initiative designed to a more participatory management style.

As such, a high level of cross-hierarchical communication was evident in the early months, but the proportion of crosshierarchical commenting and liking behavior significantly decreased throughout time as ESM became relatively more diffused among lower level retail specialists (the largest group of employees), resulting in increased interaction among specialists.

Whereas cross-hierarchical communication declined, communication across geographical boundaries increased. Hierarchical and geographical boundaries that may have previously inhibited internal organizational communication were at least partially overcome by the use of ESM, as evidenced by its active use to connect managers and employees, as well as employees in various geographical regions. This suggests that ESM helped overcome regional boundaries, because retail specialists among regions began interacting more through commenting and liking behavior throughout time.

Understanding how ESM adoption is shaped by particular organizational and cultural practices is important especially in organizations that have traditionally been characterized by formal hierarchy and lack of open communication and knowledge sharing.

\section{CONCLUSIONS}

Future research leveraging behavioral log data of ESM could explore if the network structures characterizing intraorganizational communication patterns are suggestive of or optimal for the focal team boundary-spanning activity. For instance, for ESM to support ambassadorial representation, a network structure should reveal links between the boundary spanner and higher-level managers, while groups engaging in awareness creation should exhibit more lateral relations.

On the other hand, network structures indicative of coordination or information search would consist of peer-level interactions, with the former likely displaying a smaller but denser network structure, i.e., repeated interactions, and the latter a wider yet looser structure, i.e., a large number of oneoff exchanges. Therefore, adopting a network view in future studies could improve our understanding of the interplay between ESM and team boundary spanning.

Future research should examine actual message content to assess the effects of particular types of messages and the extent to which knowledge sharing and other activities occurred. It should also probe deeper to examine how non work communication (which accounted for a substantial amount of posts) contributes to work-related collaboration and knowledge sharing.

In addition to collaborating across geographical and hierarchical boundaries, interviewees also brought up the opportunity to bridge functional and departmental boundaries within the ESM; future research should explore crossfunctional communication as well. Finally, future research should explore the relationship between culture and technology in greater depth, particularly how technological affordances may vary among cultural contexts.

\section{REFERENCES}

[1] Ellison, N. B., Gibbs, J. L., Weber, M. S. The Use of Enterprise Social Network Sites for Knowledge Sharing in Distributed Organizations: The Role of Organizational Affordances. American Behavioral Scientist, 2015, 59(1), pp. 103-123

[2] Singh, P. V., Sahoo, N., Mukhopadhyay, T. How to Attract and Retain Readers in Enterprise Blogging? Information Systems Research, 2014, 25(1), pp. 25-32

[3] Levina, N., Arriaga, M. Distinction and Status Production on UserGenerated Content Platforms: Using Bourdieu's Theory of Cultural Production to Understand Social Dynamics in Online Fields. Information Systems Research, 2014, 25(3),pp.468-488

[4] Leonardi, P. M., Huysman, M., Steinfield, C. Enterprise Social Media: Definition, History, and Prospects for the Study of Social Technologies in Organizations. Journal of Computer-Mediated Communication, 2013, 19(1), pp. 1-19

[5] Carim, L., Warwick, C. Use of social media for corporate communications by research-funding organisations in the UK. Public Relations Review, 2013, 39(5), pp. 521-525

[6] Wu, L. Social Network Effects on Productivity and Job Security: Evidence from the Adoption of a Social Networking Tool. Information Systems Research, 2013, 24(1). pp. 30-51

[7] Dewan S, Ramaprasad J. Social media, traditional media, and music sales. MIS Quart, 2014,38(1):101-121.

[8] Huang, Y., Singh, P. V., Ghose, A.. A Structural Model of Employee Behavioral Dynamics in Enterprise Social Media. Management Science, 2015, 61(12), pp. 2825-2844

[9] Aggarwal R, Gopal R, Sankaranarayanan R, Singh PV. Blog, blogger, and the firm: Can negative employee posts lead to positive outcomes? Inform. Systems Res. 2012, 23(2):306-322.

[10] Levina N, Arriaga M. Distinction and status production on usergenerated content platforms: Using Bourdieu's theory of cultural production to understand social dynamics in online fields. Inform. Systems Res, 2014, 25(3):468-488.

[11] Kwahk, K. Y., Park, D. H. The effects of network sharing on knowledge-sharing activities and job performance in enterprise social media environments. Computers in Human Behavior. 2016, vol.55, pp. 826-839

[12] Oostervink, N., Agterberg, M., Huysman, M. Knowledge Sharing on Enterprise Social Media: Practices to Cope With Institutional Complexity. Journal of Computer-Mediated Communication, 2016, 21(2), pp. 156-176

[13] Rode, H. To share or not to share: the effects of extrinsic and intrinsic motivations on knowledge-sharing in enterprise social media platforms. Journal of Information Technology, 2016, 32(1), pp. 152-165

[14] Gibbs, J. L., Eisenberg, J., Rozaidi, N. A., Gryaznova, A. The "Megapozitiv" Role of Enterprise Social Media in Enabling CrossBoundary Communication in a Distributed Russian Organization. American Behavioral Scientist, 2015, 59(1), pp. 75-102

[15] Van Osch, W., Steinfield, C. W. Team boundary spanning: strategic implications for the implementation and use of enterprise social media. Journal of Information Technology. 2016, 31(2), pp. 207-225

[16] Von Krogh, G. How Does Social Software Change Knowledge Management? Toward a Strategic Research Agenda, The Journal of Strategic Information Systems, 2012, 21(2): 154-164. 